\title{
Decreasing the incidence of prolonged air leak after right upper lobectomy with the anterior fissureless technique
}

\author{
Thomas Ng, MD, ${ }^{a}$ Beth A. Ryder, MD, ${ }^{a}$ Jason T. Machan, PhD, ${ }^{b}$ and William G. Cioffi, $\mathrm{MD}^{\mathrm{a}}$
}

Objective: For major pulmonary resections, the incidence of prolonged air leak may be highest after right upper lobectomy. Dissection through an incomplete minor fissure for pulmonary artery exposure may contribute to air leak. We evaluate the efficacy of the anterior fissureless technique in decreasing the incidence of prolonged air leak after right upper lobectomy.

Methods: Twenty-seven consecutive patients had right upper lobectomy by the classic technique of fissure dissection for pulmonary artery exposure (group A). The next 66 patients had right upper lobectomy by the anterior fissureless technique (group B).

Results: During the period of group A, we observed a higher incidence of prolonged air leak [22.2\% (6/27) vs $6.5 \%(3 / 46), P=.049]$ and an increase in hospitalization days (mean 14.8 vs 8.7 days, $P=.021$ ) after right upper lobectomy as compared with all other lobar resections. Comparing the 2 techniques for right upper lobectomy (group A vs group B), there was no difference in patient characteristics, operative characteristics, morbidity, or mortality. However, there was a difference in the time to air leak cessation (log-rank $P=.002$ ), incidence of prolonged air leak [22.2\% (6/27) vs 7.6\% (5/66), $P=.047$ ], days with chest tube (mean 9.7 vs 6.6 days, $P=.044$ ), and days in hospital (mean 14.8 vs 8.2 days, $P=.001$ ) favoring group B. No other factors predicted prolonged air leak after right upper lobectomy.

Conclusions: The anterior fissureless technique decreases the duration of air leak, incidence of prolonged air leak, days with chest tube, and days in hospital without any noted disadvantages. This technique should be considered when performing right upper lobectomy. (J Thorac Cardiovasc Surg 2010;139:1007-11)

Prolonged air leak (PAL) continues to be a common complication after major pulmonary resection. Due to the incomplete nature of the minor fissure, right upper lobectomy (RUL) is at the highest risk for PAL, with reported incidence of up to $26 \%$. ${ }^{1}$ We evaluated the efficacy of the anterior fissureless technique in decreasing the incidence of PAL after RUL.

\section{METHODS}

During a 1-year period, RUL was performed in 27 consecutive patients using the classic technique of fissure dissection with cautery to identify the pulmonary artery (PA) followed by staple division of the remaining fissure (group A). During this time period, we noticed a higher incidence of PAL after RUL as compared with all other lobar resections. We then changed our operative approach, performing the next 66 consecutive RULs over a 3-year period by the anterior fissureless technique (group B). The anterior fissureless technique involves first dividing the superior pulmonary vein (sparing the middle lobe vein) followed by division of the anterior PA trunk to the upper lobe. Using the transected upper-lobe vein stump for traction, the upper-lobe parenchyma is dissected off the PA to identify the posterior

\footnotetext{
From the Department of Surgery, ${ }^{\text {a }}$ The Warren Alpert Medical School of Brown University, and Biostatistics, ${ }^{\mathrm{b}}$ Rhode Island Hospital, Providence, RI. Disclosures: None.

Received for publication March 11, 2009; revisions received June 7, 2009; accepted for publication July 8, 2009 .

Address for reprints: Thomas Ng, MD, 2 Dudley Street, Suite 470, Providence, RI 02905 (E-mail: tng@usasurg.org).

$0022-5223 / \$ 36.00$

Copyright (c) 2010 by The American Association for Thoracic Surgery doi:10.1016/j.jtcvs.2009.07.023
}

ascending artery, which lies adjacent to the bifurcation of the upper-lobe bronchus and bronchus intermedius. The posterior ascending artery is ligated and divided. The minor fissure and the major fissure (between upper lobe and superior segment lower lobe) are divided by stapling from the anterior to the posterior direction to form one continuous staple line, thereby avoiding direct dissection into the fissure parenchyma.

In both groups, RUL was performed by posterolateral or lateral musclesparing thoracotomy, and the bronchus was divided using a stapling device. Staple line buttress material and topical sealants were not used. Patients with non-small cell lung cancer routinely had mediastinoscopy and mediastina nodal dissection at thoracotomy. All patients were extubated in the operating room. A single chest tube was used and placed on $-20 \mathrm{~cm} \mathrm{H}_{2} \mathrm{O}$ suction beyond water seal in the recovery room. Epidural analgesia was uniformly used. The next morning, the chest tube was placed on water seal without suction if the air leak was less than 3 on the leak meter with forced expiration. This chest tube management algorithm was chosen based on data by Cerfolio and colleagues, ${ }^{2}$ who showed that a leak greater than 4 was unlikely to stop by day 6 whether the chest tube was placed on water seal or suction, but was more likely to develop symptomatic pneumothorax if the chest tube was place on water seal. The chest tube was removed when air leak resolved and drainage was less than $400 \mathrm{~mL}$ in a 24-hour period. Similar to the recent multi-institutional randomized Z0030 trial by the American College of Surgeons Oncology Group, ${ }^{3}$ we defined PAL as the presence of an air leak on postoperative day 7 , although we acknowledge that there is no uniform definition among thoracic surgeons. No patients had chemical pleurodesis for PAL.

Data were derived from a prospective thoracic surgery database. All procedures were performed by a single surgeon (T.N.). Continuous variables were reported as mean \pm standard deviation and compared using Student $t$ or Mann-Whitney $U$ test. Categorical variables were reported as counts with the corresponding proportion and compared using chi-square or Fisher exact test. The probability of air leak cessation as a function of time since surgery was estimated using Kaplan-Meier method and compared using 


\author{
Abbreviations and Acronyms \\ $\mathrm{FEV}_{1}=$ forced expiratory volume in 1 second \\ PA = pulmonary artery \\ $\mathrm{PAL}=$ Prolonged air leak \\ RUL = right upper lobectomy
}

log-rank test. Multiple logistic regression analysis was used to identify independent risk factors for PAL, entering variables with $P<.10$ found at univariate analysis. All tests were 2-tailed. Statistical analysis was performed using SPSS 17.0 (SPSS Inc, Chicago, Ill) software.

Our institutional review board approved this study and waived consent as this study involved a retrospective review of data from our database and both techniques of RUL described above are acceptable methods of performing the procedure.

\section{RESULTS}

During the 1-year period of group A $(\mathrm{n}=27)$, we observed a higher incidence of PAL $[22.2 \%(6 / 27)$ vs $6.5 \%$ (3/46), $P=.049$ ] and days in hospital (mean $14.8 \pm 18.9$ vs $8.7 \pm 4.6$ days, $P=.021$ ) after RUL as compared with all other lobar resections. The observation prompted us to change our technique for RUL to the anterior fissureless technique (group B). In the first year of performing RUL by the anterior fissureless technique, PAL was seen in only 2 of 25 patients. To ensure that the favorable results were reproducible, we decided to continue with this technique for another 2 years before making comparisons with group A. Ultimately, group B consisted of 66 consecutive patients having RUL by the anterior fissureless technique over a 3-year period.

When comparing patient characteristics (Table 1) and intraoperative characteristics (Table 2), no differences were found between groups A and $\mathrm{B}$. When comparing postoperative outcomes, there was no difference in morbidity or mortality; however, patients resected using the anterior fissureless technique experienced significantly lower incidence of PAL, fewer days with chest tube, and fewer days in hospital (Table 3). Median time to air leak cessation was 6 days for group A and 4 days for group B. The time to air leak cessation after surgery, as estimated by Kaplan-Meier method (Figure 1), was shorter in patients having the anterior fissureless technique ( $P=.002$ by log-rank test).

During the period of group B, there was no difference in the incidence of PAL $[7.6 \%(5 / 66)$ vs $5.8 \%(9 / 155), P=$ $.621]$ and days in hospital (mean $8.2 \pm 4.2$ vs $7.8 \pm 4.2$ days, $P=.248$ ) after RUL as compared with all other lobar resections, respectively. There was also no difference in the incidence of PAL [6.5\% (3/46) vs 5.8\% (9/155), $P=.857]$ and days in hospital (mean $8.7 \pm 4.6$ vs $7.8 \pm 4.2$ days, $P=$ .113) when comparing non-RUL lobectomies performed during the period of group A versus the period of group B, respectively.
TABLE 1. Patient characteristics

\begin{tabular}{|c|c|c|c|}
\hline Characteristic & Group A $(n=27)$ & Group B $(n=66)$ & $\begin{array}{c}P \\
\text { value }\end{array}$ \\
\hline Age (y) & $66.5 \pm 11.0$ & $68.5 \pm 10.7$ & .415 \\
\hline Male & $15(55.6 \%)$ & $30(45.5 \%)$ & .376 \\
\hline $\mathrm{FEV}_{1}(\mathrm{~L})$ & $1.93 \pm 0.79$ & $1.94 \pm 0.75$ & .946 \\
\hline$\%$ predicted $\mathrm{FEV}_{1}(\%)$ & $74.0 \pm 23.3$ & $77.8 \pm 23.3$ & .478 \\
\hline$\%$ predicted $\mathrm{FEV}_{1}>60 \%$ & $19(70.4 \%)$ & $52(78.8 \%)$ & .386 \\
\hline$\%$ predicted DLCO $(\%)^{*}$ & $73.9 \pm 21.4$ & $71.0 \pm 19.9$ & .596 \\
\hline ASA class 3 (versus 2) & $17(63 \%)$ & $48(72.7 \%)$ & .351 \\
\hline Induction chemoradiation $\dagger$ & $1(3.7 \%)$ & $4(6.1 \%)$ & 1.00 \\
\hline Benign pathology & $2(7.4 \%)$ & $2(3 \%)$ & .577 \\
\hline \multicolumn{4}{|l|}{ Non-small cell cancer } \\
\hline Stage I & $15(62.5 \%)$ & $50(78.1 \%)$ & .139 \\
\hline Stage II & $6(25 \%)$ & $5(7.8 \%)$ & \\
\hline Stage III & $3(12.5 \%)$ & $7(10.9 \%)$ & \\
\hline Stage IV & 0 & $2(3.1 \%)$ & \\
\hline
\end{tabular}

$F E V_{l}$, Forced expiratory volume in 1 second; $D L C O$, diffusion capacity of lung for carbon monoxide; $A S A$, American Society of Anesthesiologists. *DLCO not measured in 9 patients in group A, 5 patients group B. † Concurrent chemotherapy and $5040 \mathrm{cGy}$ radiation. ‡్troup A with 1 granuloma and 1 fungal infection, group B with 1 granuloma and 1 emphysema.

By univariate analysis, only the classic technique for RUL (ie, RUL not performed by the anterior fissureless technique) was a statistically significant predictor of PAL (Table 4). When combined in a multiple logistic regression with blood loss (only variable with $P<.10$ ), the classic technique approached statistical significance at $P=.054$ (odds ratio $3.58,95 \%$ confidence interval 0.98-13.10), although blood loss was not statistically significant $(P=.449)$.

In our series of RUL (93 patients combining groups A and B), PAL resulted in significantly more days with chest tube (mean $19.9 \pm 13.8$ vs $5.8 \pm 3.5$ days, $P<.001$ ) and days in hospital (mean $14.2 \pm 4.7$ vs $9.5 \pm 11.6$ days, $P<.001)$.

\section{DISCUSSION}

The risk factors reported for PAL after pulmonary resection include low forced expiratory volume in 1 second $\left(\mathrm{FEV}_{1}\right),{ }^{4-6}$ low $\mathrm{FEV}_{1}$ to forced vital capacity ratio, ${ }^{1,4}$ upper-lobe resections, ${ }^{6,7}$ incomplete fissure, ${ }^{8}$ pleural adhesions, ${ }^{6}$ and steroid use. ${ }^{5}$ The vast majority of patients with PAL have persistent parenchymal alveolar air leak rather than true bronchopleural fistula due to bronchial stump dehiscence. ${ }^{9}$ The modern-day incidence of PAL after pulmonary lobectomy as reported by the recent American College of Surgeons Oncology Group Z0030 trial is $8 \%{ }^{3}$ Due to the incomplete nature of the minor fissure, RUL may be at the highest risk for PAL. Abolhoda and colleagues ${ }^{1}$ reported a $26 \%$ incidence of PAL after RUL, which is similar to the $22 \%$ incidence seen in our series when RUL was performed by the classic technique. This finding prompted us to change technique for RUL to the anterior fissureless technique. 
TABLE 2. Intraoperative characteristics

\begin{tabular}{|c|c|c|c|}
\hline Characteristic & $\begin{array}{c}\text { Group A } \\
(\mathbf{n}=27)\end{array}$ & $\begin{array}{c}\text { Group B } \\
(n=66)\end{array}$ & $\begin{array}{r}P \\
\text { value }\end{array}$ \\
\hline $\begin{array}{l}\text { Presence of } \\
\text { adhesions }\end{array}$ & $3(11.1 \%)$ & $6(9.1 \%)$ & .765 \\
\hline $\begin{array}{l}\text { Chest wall } \\
\text { resection }\end{array}$ & $2(7.4 \%)$ & $1(1.5 \%)$ & .201 \\
\hline Sleeve lobectomy & $1(3.7 \%)$ & $3(4.5 \%)$ & 1.00 \\
\hline Pleural tent & $1(3.7 \%)$ & $3(4.5 \%)$ & 1.00 \\
\hline $\begin{array}{l}\text { Vascularized } \\
\text { tissue flap* }\end{array}$ & $2(7.4 \%)$ & $7(10.6 \%)$ & .636 \\
\hline $\begin{array}{l}\text { Operative time, } \\
\text { min (median) }\end{array}$ & $182.8 \pm 192.6(140)$ & $136.7 \pm 41.9(127.5)$ & .276 \\
\hline $\begin{array}{l}\text { Estimated blood } \\
\text { loss, mL (median) }\end{array}$ & $266.7 \pm 270.3(200)$ & $286.4 \pm 342.3(200)$ & .439 \\
\hline $\begin{array}{l}\text { Any transfusion } \\
\text { of red cells }\end{array}$ & $9(33.3 \%)$ & $12(18.2 \%)$ & .113 \\
\hline
\end{tabular}

The anterior fissureless technique for RUL has been well described previously. ${ }^{8,10,11}$ In a randomized trial including all lobar resections, Gomez-Carol and colleagues ${ }^{8}$ found that the fissureless technique resulted in a significantly lower incidence of PAL and a higher probability of air leak cessation without an increase in morbidity or mortality when compared with the classic technique. This is similar to our results. In our series, we found that the use of the fissureless technique also resulted in fewer days with chest tube and days in hospital, whereas Gomez-Caro and associates ${ }^{8}$ did not. This was likely because we limited our evaluation only to right upper-lobe resections, the pulmonary lobe with the highest risk for air leak.

Thoracic surgeons have long sought methods to minimize air leaks after pulmonary resection, as PAL has been shown to increase days with chest tube, ${ }^{4,8}$ days in hospital, ${ }^{1,4,7,8,12,13}$ cost, ${ }^{12}$ and infectious complications such as empyema ${ }^{6,13}$ and pneumonia. ${ }^{6}$ Because it is unlikely that patient characteristics or preoperative risk factors can be significantly changed, more attention has been focused on intraoperative techniques to decrease air leak. Many intraoperative methods have been reported, such as the use of topical sealants, staple line buttress materials, pleural tent, or pneumoperitoneum, but none of these methods have clear benefit or universal applicability. Serra-Mitjans and colleagues ${ }^{14}$ performed a detail analysis of randomized trials and found that the use of topical sealants did not decrease the length of hospital stay but may increase the incidence of empyema. In a randomized study by Miller and coworkers, ${ }^{15}$ the routine use of buttress material during parenchymal stapling did not decrease air leak duration, days with chest tube, days in hospital, or cost. Randomized studies by Brunelli and colleagues ${ }^{16}$ and Okur and associates ${ }^{17}$ showed that the use of pleural tent did decrease air leak duration, days with chest tube, hospital stay, and cost; however, the potential complications of pleural tent, such as bleeding, empyema, lung restriction, and difficult reoperation, may limit its routine use. ${ }^{9}$ In a randomized trial by Cerfolio and coworkers, ${ }^{18}$ pneumoperitoneum resulted in a decrease in air leak duration and hospital stay, but this technique does not apply to upper-lobe resections. With regards to postoperative chest tube management, randomized trials by Brunelli and colleagues ${ }^{19}$ and Alphonso and associates ${ }^{20}$ showed no benefit in terms of air leak duration, days with chest tube, and days in hospital when chest tubes were placed to water seal early in the postoperative period.

In contrast to the above methods, we feel that the anterior fissureless technique is effective in decreasing air leak, can be routinely applied during RUL, and has no disadvantages-that is, no increase in operative time, blood loss,

TABLE 3. Postoperative outcomes

\begin{tabular}{|c|c|c|c|}
\hline Outcomes & Group A $(\mathbf{n}=27)$ & Group B $(\mathbf{n}=66)$ & $P$ value \\
\hline Mortality & $1(3.7 \%)$ & $1(1.5 \%)$ & .499 \\
\hline Morbidity (any complication) & $14(51.9 \%)$ & $21(31.8 \%)$ & .520 \\
\hline Prolonged air leak* & $6(22.2 \%)$ & $5(7.6 \%)$ & .047 \\
\hline Atrial fibrillation & $6(22.2 \%)$ & $9(13.6 \%)$ & .307 \\
\hline Pneumonia & $2(7.4 \%)$ & $4(6.1 \%)$ & 1.00 \\
\hline Atelectasis (bronchoscopy) & $2(7.4 \%)$ & $5(7.6 \%)$ & 1.00 \\
\hline Reintubation & $1(3.7 \%)$ & 0 & .290 \\
\hline Chylothorax & $1(3.7 \%)$ & 0 & .290 \\
\hline Empyema & 0 & $1(1.5 \%)$ & 1.00 \\
\hline Wound infection & 0 & $1(1.5 \%)$ & 1.00 \\
\hline Ileus & 0 & $1(1.5 \%)$ & 1.00 \\
\hline Urinary tract infection & 0 & $1(1.5 \%)$ & 1.00 \\
\hline Days with chest tube (median) & $9.7 \pm 9.4(7)$ & $6.6 \pm 6.0(5)$ & .044 \\
\hline Days in hospital (median) & $14.8 \pm 18.9(10)$ & $8.2 \pm 4.2(7)$ & .001 \\
\hline
\end{tabular}

*Three patients in group A and 1 in group B were discharge with Heimlich valve. All air leaks were due to parenchymal leaks. No patient had bronchopleural fistula due to bronchial stump dehiscence. 


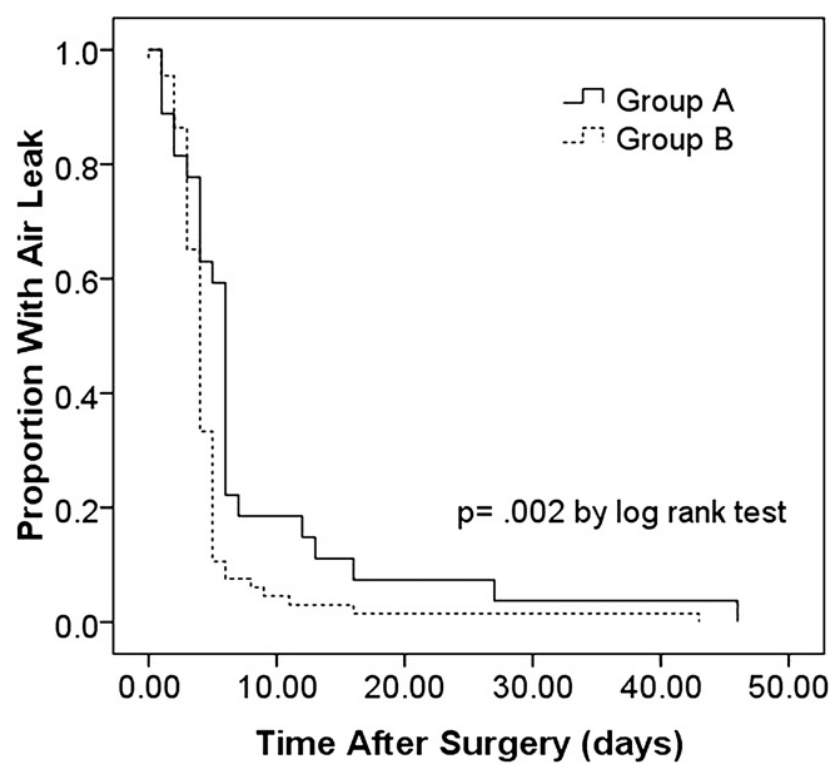

FIGURE 1. Probability of air leak cessation as a function of time since surgery as estimated by Kaplan-Meier method. Group A, right upper lobectomy by classic technique. Group B, right upper lobectomy by anterior fissureless technique.

morbidity, or mortality as shown by our data. Historically, the classic technique for RUL enabled safe identification of the posterior ascending PA within the fissure. However, we universally found no difficulty in identifying this artery with the anterior fissureless technique. Today, this technique is commonly used during RUL by video-assisted thoracic surgery. ${ }^{21}$ Circumstances where the anterior fissureless technique should not be attempted include the presence of fissure involvement by the primary tumor or by adherent interlobar adenopathy. In these situations, it is unlikely that the classic technique would be of additional benefit, and a bilobectomy or pneumonectomy would likely be required.

Our study has several limitations. First, this was a retrospective study. However, we believe that the prospective database from which we drew contained accurately reported outcomes for our purposes. Second, the number of patients in the study is small, which may offer explanation for why we failed to detect significant effects from many conventional risk factors. Third, the 2 cohorts of patients underwent surgical procedure during consecutive periods rather than in a randomized fashion. Therefore, it is possible that our data were biased by surgeon's increased awareness of air leak and by surgical experience, which is gained over time. However, we feel that such bias was minimal as the single surgeon who performed all the resections had a much greater experience with the classic technique than with the anterior fissureless technique prior to the study period, thus the outcome of group A patients should have been favored. Also the incidence of PAL and the days in hospital for non-RUL lobectomies performed during the period of group A versus the period of group B did not differ. In addition, because the

TABLE 4. Univariate analysis for risk factors for PAL

\begin{tabular}{|c|c|c|c|}
\hline Characteristic & PAL $(\mathbf{n}=\mathbf{1 1})$ & No PAL $(\mathbf{n}=82)$ & $P$ value \\
\hline Age (y) & $66.2 \pm 11.3$ & $68.1 \pm 10.8$ & .573 \\
\hline Male & $4(36.4 \%)$ & $41(50 \%)$ & .395 \\
\hline $\mathrm{FEV}_{1}(\mathrm{~L})$ & $1.78 \pm .73$ & $1.96 \pm .76$ & .461 \\
\hline$\%$ predicted $\mathrm{FEV}_{1}(\%)$ & $74.1 \pm 21.3$ & $77.0 \pm 23.6$ & .699 \\
\hline$\%$ predicted $\mathrm{FEV}_{1}>60 \%$ & $8(72.7 \%)$ & $63(76.8 \%)$ & .764 \\
\hline$\%$ predicted DLCO $(\%)^{*}$ & $61.0 \pm 21.2$ & $72.9 \pm 19.8$ & .114 \\
\hline ASA class 3 (vs 2) & $6(54.5 \%)$ & $59(72 \%)$ & .237 \\
\hline Induction chemoradiation & 0 & $5(6.1 \%) \dagger$ & 1.00 \\
\hline Presence of adhesions & $1(9.1 \%)$ & $8(9.8 \%)$ & 1.00 \\
\hline Chest wall resection & 0 & $3(3.7 \%)$ & 1.00 \\
\hline Sleeve lobectomy & 0 & $4(4.9 \%)$ & 1.00 \\
\hline Classic technique $\ddagger$ & $6(54.5 \%)$ & $21(25.6 \%)$ & .047 \\
\hline Pleural tent & 0 & $4(4.9 \%)$ & 1.00 \\
\hline Vascularized tissue flap & 0 & $9(11 \%) \S$ & .592 \\
\hline Operative time, $\min$ (median) & $125.5 \pm 40.0(120)$ & $153.4 \pm 116.3(130)$ & .241 \\
\hline Estimated blood loss, mL (median) & $340.9 \pm 720.7(100)$ & $272.6 \pm 230.0(200)$ & .082 \\
\hline Any transfusion of red cells & $2(18.2 \%)$ & $19(23.2 \%)$ & .710 \\
\hline Benign pathology & 0 & $4(4.9 \%) \|$ & 1.00 \\
\hline \multicolumn{4}{|l|}{ Non-small cell cancer } \\
\hline Stage I & $7(63.6 \%)$ & $58(75.3 \%)$ & .337 \\
\hline Stage II & $1(9.1 \%)$ & $10(13.0 \%)$ & \\
\hline Stage III & $3(27.3 \%)$ & $7(9.1 \%)$ & \\
\hline Stage IV & 0 & $2(2.6 \%)$ & \\
\hline
\end{tabular}

PAL, Prolonged air leak; $F E V_{l}$, forced expiratory volume in 1 second; $D L C O$, diffusion capacity of lung for carbon monoxide; ASA, American Society of Anesthesiologists. *DLCO not measured in 3 patients having PAL, in 11 patients not having PAL. †Concurrent chemotherapy and 5040-cGy radiation. ‡Not performing right upper lobectomy by the anterior fissureless technique. $\S$ Seven intercostal muscle and 2 pericardial fat. \|Two granuloma, 1 fungal infection and 1 emphysema. 
surgeries were performed by the same individual for both sets of patients, the effect of surgeon was a constant. Finally, our infrequent use of Heimlich valves may have impacted our measure of days in hospital relative to other institutions, as these valves allow patients with air leaks to be discharged early. Our experience has been that the infrequent use of Heimlich valves was driven mainly by patient preference, as many patients feared going home with a chest tube, rather than by physician preference. Ultimately, we feel this served as an incidental advantage in terms of data acquisition. Having patients in-hospital until air leak resolution allows the data of air leak duration to be more precise, as its presence or absence is assessed daily by a physician.

In conclusion, air leak continues to be a common complication of major pulmonary resection, especially after RUL. The anterior fissureless technique decreases the duration of air leak and the incidence of PAL without any noted disadvantages. In the absence of malignant involvement of the fissure, this technique should be considered when performing RUL. A randomized trial can be performed to confirm our conclusions.

\section{References}

1. Abolhoda A, Liu D, Brooks A, Burt M. Prolonged air leak following radical upper lobectomy: an analysis of incidence and possible risk factors. Chest. 1998;113: 1507-10.

2. Cerfolio RJ, Bass C, Katholi CR. Prospective randomized trial compares suction versus water seal for air leaks. Ann Thorac Surg. 2001;71:1613-7.

3. Allen MS, Darling GE, Pechet TT, Mitchell JD, Herndon JE 2nd, Landreneau RJ, et al. Morbidity and mortality of major pulmonary resections in patients with early-stage lung cancer: initial results of the randomized, prospective ACOSOG Z0030 trial. Ann Thorac Surg. 2006;81:1013-9.

4. Stolz AJ, Schutzner J, Lischke R, Simonek J, Pafko P. Predictors of prolonged air leak following pulmonary lobectomy. Eur J Cardiothorac Surg. 2005;27:334-6.

5. Cerfolio RJ, Bass CS, Pask AH, Katholi CR. Predictors and treatment of persistent air leaks. Ann Thorac Surg. 2002;73:1727-30.
6. Brunelli A, Monteverde M, Borri A, Salati M, Marasco RD, Fianchini A. Predictors of prolonged air leak after pulmonary lobectomy. Ann Thorac Surg. 2004;77: 1205-10.

7. Okereke I, Murthy SC, Alster JM, Blackstone EH, Rice TW. Characterization and importance of air leak after lobectomy. Ann Thorac Surg. 2005;79:1167-73.

8. Gomez-Caro A, Calvo MJ, Lanzas JT, Chau R, Cascales P, Parrilla P. The approach of fused fissures with fissureless technique decreases the incidence of persistent air leak after lobectomy. Eur J Cardiothorac Surg. 2007;31:203-8.

9. Rice TW, Okereke IC, Blackstone EH. Persistent air-leak following pulmonary resection. Chest Surg Clin N Am. 2002;12:529-39.

10. Temes RT, Willms CD, Endara SA, Wernly JA. Fissureless lobectomy. Ann Thorac Surg. 1998;65:282-4.

11. Loran DB, Woodside KJ, Cerfolio RJ, Zwischenberger JB. Predictors of alveolar air leaks. Chest Surg Clin N Am. 2002;12:477-88.

12. Varela G, Jimenez MF, Novoa N, Aranda JL. Estimating hospital costs attributable to prolonged air leak in pulmonary lobectomy. Eur J Cardiothorac Surg. 2005;27:329-33.

13. Brunelli A, Xiume F, Al Refai M, Salati M, Marasco R, Sabbatini A. Air leaks after lobectomy increase the risk of empyema but not of cardiopulmonary complications: a case-matched analysis. Chest. 2006;130:1150-6.

14. Serra-Mitjans M, Belda-Sanchis J, Rami-Porta R. Surgical sealant for preventing air leaks after pulmonary resections in patients with lung cancer. Cochrane Database Syst Rev. 2005:CD003051.

15. Miller JI Jr, Landreneau RJ, Wright CE, Santucci TS, Sammons BH. A comparative study of buttressed versus nonbuttressed staple line in pulmonary resections. Ann Thorac Surg. 2001;71:319-22.

16. Brunelli A, Al Refai M, Monteverde M, Borri A, Salati M, Sabbatini A, Fianchini A. Pleural tent after upper lobectomy: a randomized study of efficacy and duration of effect. Ann Thorac Surg. 2002;74:1958-62.

17. Okur E, Kir A, Halezeroglu S, Alpay AL, Atasalihi A. Pleural tenting following upper lobectomies or bilobectomies of the lung to prevent residual air space and prolonged air leak. Eur J Cardiothorac Surg. 2001;20:1012-5.

18. Cerfolio RJ, Holman WL, Katholi CR. Pneumoperitoneum after concomitant resection of the right middle and lower lobes (bilobectomy). Ann Thorac Surg. 2000;70:942-6.

19. Brunelli A, Monteverde M, Borri A, Salati M, Marasco RD, Al Refai M, et al Comparison of water seal and suction after pulmonary lobectomy: a prospective, randomized trial. Ann Thorac Surg. 2004;77:1932-7.

20. Alphonso N, Tan C, Utley M, Cameron R, Dussek J, Lang-Lazdunski L, et al. A prospective randomized controlled trial of suction versus non-suction to the under-water seal drains following lung resection. Eur J Cardiothorac Surg. 2005; 27:391-4.

21. McKenna RJ Jr. The current status of video-assisted thoracic surgery lobectomy. Chest Surg Clin N Am. 1998;8:775-85. 